\title{
FAKTOR RESIKO RETINOPATI DIABETIKA : A CASE - CONTROL
}

\author{
Iis Noventi \\ (Universitas Nahdlatul Ulama Surabaya, Fakultas Keperawatan kebidanan, \\ Program Studi S1 Keperawatan, Email: iisnoventi@unusa.ac.id) \\ Siti Damawiyah \\ (Universitas Nahdlatul Ulama Surabaya, Fakultas Keperawatan kebidanan, \\ Program Studi D3 Keperawatan, Email: damasiti@unusa.ac.id)
}

\begin{abstract}
ABSTRAK
Retinopati Diabetika adalah komplikasi okular umum Diabetes Mellitus dan dianggap sebagai salah satu penyebab utama kehilangan penglihatan. Tujuan penelitian menentukan faktor -faktor resiko pengembangan DR di RSMM Jawa Timur Surabaya. Metode yang digunakan studi kasus-kontrol pengumpulan data dilakukan ada atau tidaknya DR ditentukan oleh dokter mata. Hasil menunjukkan DR NPDR pasien perempuan dominan (60\%), pada PDR pasien laki-laki dominan (60\%). DR NPDR pasien dengan tidak mempunyai hipertensi dominan $(53,3 \%)$, pada PDR pasien dengan hipertensi dominan (73,3\%). DR NPDR pasien dengan dislipidemia dominan (60\%), pada PDR pasien dengan dislipidemia dominan (63,3\%). Umur terendah pasien DR NPDR ditemukan adalah 39 tahun, dan tertinggi 82 tahun. Pada PDR umur terendah adalah 40 tahun dan umur tertinggi adalah 63 tahun. Gula darah terendah pada pasien NPDR adalah $94 \mathrm{mg} / \mathrm{dl}$, dan tertinggi $571 \mathrm{mg} / \mathrm{dl}$. Pada PDR gula darah terendah adalah $108 \mathrm{mg} / \mathrm{dl}$, dan tertinggi $453 \mathrm{mg} / \mathrm{dl}$. Lama menderita DM terendah pada NPDR adalah 1 tahun, dan terlama 50 tahun. Pada PDR terendah 1 tahun dan terlama 20 tahun. Dengan demikian pasien diabetes perempuan, dengan dislipidemia, umur $>30$ s.d $<85$ tahun, dengan lama menderita 1 s.d $\leq 50$ tahun mempunyai resiko NPDR. Sedangkan pasien diabetes laki-laki, hipertensi dan dislipidemia, umur $\geq 40$ s.d $<65$ tahun, dengan lama menderita $1 \mathrm{~s} . \mathrm{d} \leq 20$ tahun mempunyai resiko PDR.
\end{abstract}

Kata Kunci: Retinopati Diabetes, faktor resiko, NPDR, PDR

\section{ABSTRACT}

Diabetic retinopathy is a common ocular complication of Diabetes Mellitus and is considered one of the main causes of vision loss. This research to determine risk factors for DR development in RSMM East Java Surabaya. The research methode was case-control study of data collection was carried out whether or not there was a DR determined by an ophthalmologist. Results showed DR NPDR of female patients was dominant (60\%), in PDR of dominant male patients (60\%). DR NPDR patients with no dominant hypertension (53.3\%), in PDR patients with dominant hypertension (73.3\%). DR NPDR of patients with dominant dyslipidemia (60\%), in PDR of patients with dominant dyslipidemia (63.3\%). The lowest age for DR NPDR patients was found to be 39 years, and the highest was 82 years. The lowest age PDR is 40 years and the highest age is 63 years. The lowest blood sugar in NPDR patients was $94 \mathrm{mg} / \mathrm{dl}$, and the highest was $571 \mathrm{mg}$ / dl. The lowest blood sugar PDR was $108 \mathrm{mg} / \mathrm{dl}$, and the highest was $453 \mathrm{mg} /$ $d l$. The lowest duration of diabetes in NPDR is 1 year, and the longest is 50 years. At the lowest PDR 1 year and the longest 20 years. So, female diabetic patients, 
with dyslipidemia, age $>30$ until $<85$ years, with a duration of 1 until $\leq 50$ years have a risk of NPDR. While male diabetic patients, hypertension and dyslipidemia, age.$d 40$ until <65 years, with a duration of 1 until 20 years have a risk of PDR.

Keywords: Retinopati Diabetes, Risk Factor, NPDR, PDR

\section{PENDAHULUAN}

Diabetes mellitus (DM) adalah
sindrom metabolik dengan
peningkatan prevalensi dan tingkat
mortalitas yang tinggi. Diabetes
melitus (DM) merupakan suatu
penyakit metabolik yang ditandai
dengan hiperglikemia atau peningkatan kadar gula darah yang kronis dan bervariasi. Hal ini dapat disebabkan karena kelainan sekresi insulin, kerja insulin atau keduanya. Selain itu, etiologi dari DM sangat kompleks, baik gaya hidup yang tidak sehat, lingkungan, genetik, dan lainnya (PERKENI, 2006). Data terbaru dari WHO (Badan Kesehatan Dunia), Indonesia menduduki peringkat keempat terbesar dalam jumlah penyandang DM di dunia. Indonesia menempati urutan keempat setelah India, Cina, dan Amerika. Penderita DM di seluruh dunia hampir mencapai 150 juta orang dan di Indonesia mencapai 8,4 juta orang. Jumlah tersebut akan meningkat dua kali lipat pada tahun 2025 dan paling banyak terjadi di negara-negara berkembang, terutama di Asia Tenggara (Karyadi, 2006). DM tipe 2 seringkali tidak dapat dirasakan gejalanya pada stadium awal, dan tetap tidak terdiagnosis selama bertahun-tahun sampai terjadi berbagai komplikasi akibat penyakit ini (Darmono, 2007). Salah satu komplikasi mikrovaskular yang dapat terjadi pada diabetes melitus adalah retinopati. Retinopati Diabetik (RD) adalah komplikasi okular umum DM dan dianggap sebagai salah satu penyebab utama kehilangan penglihatan dan gangguan penglihatan pada orang dewasa. RD telah dianggap berkorelasi dengan banyak komplikasi terkait diabetes lainnya, seperti nefropati, neuropati perifer, kepadatan tulang rendah dan kejadian kardiovaskular, yang semuanya menurunkan kualitas hidup dan meningkatkan angka kematian (Munazir, Shareem, 2017).

Retinopati diabetik merupakan penyebab kebutaan yang paling sering ditemukan pada usia dewasa antara 20-74 tahun. Pasien diabetes memiliki resiko 25 kali lebih mudah mengalami kebutaan dibanding nondiabetes. Resiko mengalami retinopati meningkat sejalan dengan lamanya diabetes. Pada diabetes tipe 2 ketika diagnosis ditegakkan, sekitar $25 \%$ pasien sudah menderita retinopati diabetik nonproliferatif (background retinopathy) yaitu bentuk yang paling ringan dari retinopati diabetik dan sering tidak memperlihatkan gejala. Setelah 20 tahun, prevalensi retinopati diabetika meningkat menjadi lebih dari $60 \%$ dalam berbagai derajat. Organisasi Kesehatan Dunia (WHO) tahun 2004 melaporkan 4,8 persen penduduk di seluruh dunia menjadi buta akibat retinopati diabetik. Dalam urutan penyebab kebutaan secara global, retinopati diabetik menempati urutan ke-4 setelah katarak, glaukoma, dan 
komorbiditas

(hipertensi,

degenerasi macula (Suyono, dkk, 2006). Pasien wanita yang lebih tua dengan durasi penyakit yang lebih lama diketahui memiliki risiko lebih besar untuk terjadinya retinopati diabetika. Selain itu, memiliki komplikasi Nefropati, kontrol glikemik yang buruk, tingkat lipid yang tinggi, lama menderita diabetes, hiperglikemia atau hipertensi juga telah dilaporkan menjadi faktor risiko retinopati diabetika. Namun, retinopati diabetika dan faktor risiko retinopati diabetika biasanya mendapat sedikit perhatian, dan kepatuhan pada pemeriksaan mata sering terabaikan (Sanjeev, Panwar, 2014)

Melalui penelitian ini kami berusaha untuk mengetahui dan memberikan informasi mengenai factor - factor resiko retinopati diabetika pada pasien DM Tipe 2 di Rawat jalan RSMM Surabaya. Data hasil penelitian ini diharapkan dapat dijadikan salah satu data dasar dalam penyempurnaan program pengelolaan DM serta upaya pencegahan komplikasi DM sedini mungkin.

\section{METODE PENELITIAN}

Sebuah studi kasus-kontrol dilakukan pada pasien rawat jalan di RSMM Jawa Timur Surabaya, Rekam medis pasien diabetes pada periode antara Agustus 2018 sampai Oktober 2018 dianalisis. Kasus dan kontrol berhubungan dengan rekaman pasien dengan DR NPDR dan DR PDR masing - masing 30 pasien dengan menggunakan desain penelitian Descriptive retrospective. Data dikumpulkan menggunakan kuesioner termasuk: data demografi (jenis kelamin dan usia), GDA, profil DM (Durasi diabetes) dan dislipidemia). Diagnosa pertama kali dipilih untuk ada atau tidaknya DR, ditentukan oleh dokter mata menurut temuan klinis dikonfirmasi dengan ophthalmoscopy langsung dan tidak langsung mengikuti klasifikasi retinopati diabetik klinis. Pasien dengan kekeruhan lensa, pelebaran pupil bisa, ibu hamil dan di curigai gloukoma sudut sempit di keluarkan dari penelitian. Mengenai komorbiditas, diagnosis sepenuhnya didasarkan pada pemeriksaan klinis, mempertimbangkan riwayat klinis dan tes laboratorium. Hipertensi ditetapkan sebagai tekanan darah $\geq 140$ / 90 mmHg, dislipidemia ditetapkan kolesterol total $\geq 200 \mathrm{mg}$ / dL. Untuk menganalisis kenaikan angka kejadian retinopati diabetik yang signifikan adalah dengan cara melihat persentase dari jenis kelamin, komorbiditas, dan GDA. Sedangkan untuk umur dan lama menderita menggunakan nilai mean dan standar deviasi.

\section{HASIL}

Sebanyak 60 pasien dengan RD, 30 kasus dan 30 kontrol. Analisis deskriptif persentase pasien perempuan adalah $60 \%$ untuk NPDR dan laki - laki $60 \%$ untuk PDR. DR NPDR pasien dengan tidak mempunyai hipertensi dominan $(53,3 \%)$, pada PDR pasien dengan hipertensi dominan (73,3\%). DR NPDR pasien dengan dislipidemia dominan (60\%), pada PDR pasien dengan dislipidemia dominan (63,3\%). Umur terendah pasien DR NPDR ditemukan adalah 39 tahun, dan tertinggi 82 tahun. Pada PDR umur terendah adalah 40 tahun dan umur tertinggi adalah 63 tahun. Gula darah terendah pada pasien NPDR 
adalah $94 \mathrm{mg} / \mathrm{dl}$, dan tertinggi 571 $\mathrm{mg} / \mathrm{dl}$. Pada PDR gula darah terendah adalah $108 \mathrm{mg} / \mathrm{dl}$, dan tertinggi $453 \mathrm{mg} / \mathrm{dl}$. Lama menderita DM terendah pada NPDR adalah 1 tahun, dan terlama 50 tahun. Pada PDR terendah 1 tahun dan terlama 20 tahun.

Tabel 1. Distribusi Jenis Kelamin Pada Pasien NPDR di RSMM Jawa Timur Surabaya Tahun 2018

Sumber: Iis (2018)

\begin{tabular}{lrcc}
\hline No & \multicolumn{1}{c}{ Jenis Kelamin } & Frekuensi & Persentase \\
\hline 1. & Laki - laki & 40 & $40 \%$ \\
\hline 2. & Perempuan & 60 & $60 \%$ \\
\hline \multicolumn{2}{r}{ Total } & 100 & $100 \%$ \\
\hline
\end{tabular}

Tabel 2. Distribusi Jenis Kelamin Pada Pasien PDR di RSMM Jawa Timur Surabaya Tahun 2018

Sumber: Iis (2018)

\begin{tabular}{lrcc}
\hline No & Jenis Kelamin & Frekuensi & Persentase \\
\hline 1. & Laki - laki & 60 & $60 \%$ \\
\hline 2. & Perempuan & 40 & $40 \%$ \\
\hline \multicolumn{2}{r}{ Total } & 100 & $100 \%$ \\
\hline
\end{tabular}

Tabel 3. Distribusi Menderita Hipertensi Pada Pasien NPDR di RSMM Jawa Timur Surabaya Tahun 2018

Sumber: Iis (2018)

\begin{tabular}{llccc}
\hline No & & Hipertensi & Frekuensi & Persentase \\
\hline 1. & Tidak & & 16 & $53.3 \%$ \\
\hline 2. & Ya & & 14 & $46.7 \%$ \\
\hline & & Total & 100 & $100 \%$ \\
\hline
\end{tabular}

Tabel 4. Distribusi Menderita Hipertensi Pada Pasien PDR di RSMM Jawa Timur Surabaya Tahun 2018

Sumber: Iis (2018)

\begin{tabular}{lllcc}
\hline No & & Hipertensi & Frekuensi & Persentase \\
\hline 1. & Tidak & & 8 & $26.7 \%$ \\
\hline 2. & Ya & & 22 & $73.3 \%$ \\
\hline & & Total & 100 & $100 \%$ \\
\hline
\end{tabular}


Tabel 5. Distribusi Menderita Dislipidemia Pada Pasien NPDR di RSMM Jawa Timur Surabaya Tahun 2018

Sumber: Iis (2018)

\begin{tabular}{llccc}
\hline No & & Dislipidemia & Frekuensi & Persentase \\
\hline 1. & Tidak & & 12 & $40 \%$ \\
\hline 2. & Ya & & 18 & $60 \%$ \\
\hline & & Total & 100 & $100 \%$ \\
\hline
\end{tabular}

Tabel 6. Distribusi Menderita Dislipidemia Pada Pasien PDR di RSMM Jawa Timur Surabaya Tahun 2018

Sumber: Iis (2018)

\begin{tabular}{llccc}
\hline No & & Dislipidemia & Frekuensi & Persentase \\
\hline 1. & Tidak & & 11 & $36.7 \%$ \\
\hline 2. & Ya & & 19 & $63.3 \%$ \\
\hline & & Total & 100 & $100 \%$
\end{tabular}

Tabel 7. Umur, GDA, Lama Sakit Terendah dan Tertinggi Pasien NPDR di RSMM Jawa Timur Surabaya Tahun 2018

Sumber: Iis (2018)

\begin{tabular}{|l|r|r|r|r|}
\hline & $\mathrm{N}$ & Minimum & Maximum & \multicolumn{1}{c|}{ Mean } \\
\hline Umur & 30 & 39.00 & 82.00 & 58.4000 \\
GDA & 30 & 94.00 & 571.00 & 220.7667 \\
Lama sakit & 30 & 1.00 & 50.00 & 10.5517 \\
& & & & \\
Valid N (listwise) & & & & \\
\hline
\end{tabular}

Tabel 8. Umur, GDA, Lama Sakit Terendah dan Tertinggi Pasien PDR di RSMM Jawa Timur Surabaya Tahun 2018

Sumber: Iis (2018)

\begin{tabular}{|l|r|r|r|r|}
\hline & $\mathrm{N}$ & Minimum & Maximum & \multicolumn{1}{c|}{ Mean } \\
\hline Umur & 30 & 39.00 & 82.00 & 58.4000 \\
GDA & 30 & 94.00 & 571.00 & 220.7667 \\
Lama sakit & 30 & 1.00 & 50.00 & 9.25660 \\
& & & & \\
Valid N (listwise) & 30 & & & \\
\hline
\end{tabular}




\section{PEMBAHASAN}

Berdasarkan hasil yang tertera di tabel 1 didapatkan bahwa pasien perempuan pada DR NPDR lebih banyak di bandingkan pasien lakilaki. Hal ini sesuai dengan hasil penelitian yang dilakukan oleh Jamaludin dkk yang mengemukakan bahwa lebih banyak pasien retinopati diabetik pada perempuan dibandingkan dengan pasien lakilaki. Tingginya angka retinopati pada wanita dikaitkan dengan tingginya angka kegemukan pada wanita terkait genetik dan pola hidup yang merupakan faktor resiko DM. Hormon estrogen merupakan hormon seks dominan pada wanita, kadar hormon estrogen yang tinggi dapat menurunkan leptin yang berperan dalam penekan napsu makan di hipotalamus, akibatnya asupan makanan tidak terkontrol, sehingga dapat menyebabkan penumpukan jaringan lemak berlebih disertai tingginya kadar gula darah akibat terjadinya penurunan sensitifitas jaringan perifer terhadap insulin. ${ }^{13}$ Penurunan hormon Estrogen dan peningkatan hormon Oestradiol dan Testoterone yang dapat meningkatkan resiko diabetes mellitus pada perempuan Postmenopause.

Berdasarkan hasil yang tertera di tabel 2 didapatkan bahwa pasien laki-laki pada DR PDR lebih banyak di bandingkan pasien perempuan. Hal ini sesuai dengan hasil penelitian yang dilakukan oleh Eksys $G$ yang mengemukakan bahwa Berdasarkan data diatas dapat disimpulkan bahwa laki-laki lebih banyak mengidap PDR dibandingkan perempuan. Hal ini disebabkan akibat laki-laki cenderung tidak terlalu mengontrol kadar gula darah dengan baik dibandingkan dengan perempuan.

Berdasarkan teori laki-laki memang lebih beresiko mengidap diabetes pada usia $<60$ tahun daripada perempuan, namun sebaliknya pada usia > 60 tahun perempuan lebih banyak mengidap diabetes dibandingkan dengan lakilaki. ${ }^{2,7}$ Penelitian oleh Raman menunjukkan jenis kelamin laki-laki merupakan faktor resiko RD karena lebih banyak dipengaruhi oleh kebiasaan merokok dan minum alkohol. Berdasarkan riwayat hipertensi yang tertera di tabel 3 didapatkan bahwa pasien RD NPDR tidak banyak yang di sertai hipertensi dari pada yang hipertensi. Hasil penelitian Appropriate Blood Pressure Control in Diabetes (ABCD) pada tahun 2000 dengan jumlah sampel 470 menyatakan bahwa tidak ada perbedaan progresivitas retinopati diabetic antara kelompok dengan kontrol tekanan darah ketat (diastol < 75 $\mathrm{mmHg}$ ) dan kelompok dengan kontrol tekanan darah tidak ketat (diastol antara 80-89 $\mathrm{mmHg}$ ) selama 5,3 tahun (Shah C A, 2015) .

Pebedaan hasil penelitian di duga karena meningkatnya risiko mengalami retinopati diabetik pada pasien diabetes melitus dengan hipertensi belum diketahui secara pasti mekanismenya. Kemungkina hal ini berkaitan dengan pemicuan ganda pada aktivitas biokimia yang berkaitan dengan endotel vaskuler, terutama VGEFs. Berdasarkan riwayat hipertensi yang tertera di tabel 4 didapatkan bahwa pasien RD PDR lebih banyak yang disertai hipertensi daripada yang tidak hipertensi. Hasil penelitian Yulia Annisa pada tahun 2017 menyatakan bahwa Pasien diabetes mellitus 
dengan hipertensi memiliki resiko mengalami retinopati 12 kali lebih besar dari pada non hipertensi. Berdasarkan tabel 5 dan tabel 6 didapatkan bahwa pasien RD NPDR dan PDR lebih banyak di sertai dislipidemia. Menurut penelitian ETDRS, peningkatan progresivitas dari retinopati diabetik terjadi akibat kontrol gula darah yang tidak baik dengan parameter $\mathrm{HbA} 1 \mathrm{c}$ yang lebih dari $7 \%$, tekanan darah yang tinggi dan keadaan hiperkolesterolemia.1-4 Ketiga faktor risiko tersebut dialami oleh pasien ini sehingga terjadi progresivitas penyakit yang cepat. Berdasarkan rentang umur yang tertera di tabel 7 di dapatkan bahwa umur terendah pasien RD NPDR yang ditemukan adalah 39 tahun, sedangkan umur tertinggi adalah 82 tahun. Berdasarkan data tabel diatas didapatkan dari 30 pasien NPDR tidak didapatkan pasien yang berumur kurang dari 20 tahun.

Berdasarkan data diatas dapat disimpulkan bahwa tidak terdapat peningkatan angka kejadian retinopati diabetik NPDR yang signifikan dari usia $<20$ tahun sampai $>85$ tahun. Berdasarkan rentang umur yang tertera di tabel 8 di dapatkan bahwa umur terendah pasien RD PDR yang ditemukan adalah 40 tahun, sedangkan umur tertinggi adalah 63 tahun. Berdasarkan data tabel diatas didapatkan dari 30 pasien NPDR dan 30 pasien PDR tidak didapatkan pasien yang berumur kurang dari 20 tahun. Usia merupakan salah satu faktor resiko dalam proses terjadinya RD. Pertambahan usia mulai usia 40 tahun dapat menurunkan fungsi tubuh yang disebabkan oleh proses apoptosis sel. Keadaan hiperglikemia yang kronis, reaksi inflamasi dan stress oksidatif mempercepat terjadinya apoptosis sel di retina sehingga mengakibatkan terjadinya keadaan retinopati. Kedua hal tersebut menjelaskan mengapa orang tua lebih rentan terhadap kejadian DR yang akhirnya ditemukan meningkat dengan bertambahnya usia. ${ }^{21}$ Berdasarkan tabel 7 dan tabel 8 didapatkan bahwa pasien RD NPDR dan PDR lebih banyak di sertai hiperglikemia. Gangguan mikrovaskular pada retina disebabkan oleh keadaan hiperglikemia pada pembuluh darah. Keadaan hiperglikemia pada darah menyebabkan terjadinya kerusakan endotel. Selain itu terjadi kehilangan perisit dan penebalan membran basal dari pembuluh darah sehingga memicu terjadinya oklusi kapiler dan iskemi pembuluh darah. Keadaan ini menyebabkan dekompensasi fungsi endotel sebagai sawar darah retina dan terjadi edema retina.

Berdasarkan rentang lama menderita yang tertera di tabel 7 di dapatkan bahwa lama menderita terendah pasien RD NPDR yang ditemukan adalah 1 tahun, sedangkan lama menderita tertinggi adalah 50 tahun. Sedangkan di tabel 8 di dapatkan bahwa lama menderita terendah pasien RD PDR yang ditemukan adalah 1 tahun, sedangkan lama menderita tertinggi adalah 20 tahun. Penelitian oleh Massimo et al menunjukkan rata-rata RD terjadi 5 tahun setelah pasien terdiagnosa DM.20 Selain itu, pada durasi DM 510 tahun sudah terdapat perubahan vaskular yang cukup signifikan seperti mikroaneurisma, cotton wool spot, perdarahan intraretinal dan edema makula. 


\section{SIMPULAN}

Pasien diabetes perempuan, dengan dislipidemia, umur $>30$ s.d $<$ 85 tahun, dengan lama menderita 1 s.d $\leq 50$ tahun mempunyai resiko NPDR. Sedangkan pasien diabetes laki-laki, hipertensi dan dislipidemia, umur $\geq 40$ s.d $<65$ tahun, dengan lama menderita 1 s.d $\leq 20$ tahun mempunyai resiko PDR. Retinopati diabetik merupakan salah satu komplikasi mikrovaskular pada DM. Penegakan diagnosis retinopati diabetik sedini mungkin perlu dilakukan melalui upaya skrining rutin pada pasien DM. Edukasi dan promosi kesehatan seperti penyuluhan dan pemberian pamflet berisi informasi tentang komplikasi berupa RD diharapkan dapat meningkatkan kesadaran penderita DM akan bahaya komplikasi berupa RD.

\section{DAFTAR PUSTAKA}

Darmono. (2007). Diabetes Mellitus Ditinjau Dari Berbagai Aspek Penyakit Dalam. Semarang: Badan Penerbit Universitas Diponegoro.

Karyadi, E. (2006). Kiat Mengatasi Penyakit Diabetes, Hiperkolesterolemia, Stroke. Jakarta: PT. Intisari Mediatama

Munazir, Samreen. (2017). Awareness of retinal screening in patients with Type 2 diabetes mellitus: Are we meeting standards of care?. Asian Journal of Medical Sciences ; volume 8: 24679100
Yunia Annisa, M. Fadhol. (2017). perbandingan resiko terjadinya retiopati diabetik antara pasien hipertensi dan non hipertensi yang mengidap diabetes mellitus. Medisains. 2017; Vol 15 No 1

Eksys, G.,Harry, J.,Laya, R. (2015).Usia Harapan Hidup Dengan Retinopati Diabetik. Jurnal e-Clinic (eCl), Volume 3, Nomor 1, Januari-April 2015

Sanjeev, Panwar, (2014). Glycaemic status is an important risk factor for the occurrence of diabetic retinopathy in newly diagnosed type 2 diabetic patient. Asian Journal of Medical Sciences, 2017; volume $6: 3126-11745$

Yellien R Manullang, Laya Rares. (2014). prevalensi retinopati diabetika pada pasien diabetes melitus tipe 2 . Portal Garuda Dikti.

Ni Made Sintia Anggia Sari, Made Ratna Saraswati. (2011). prevalensi retinopati diabetika pada pasien diabetes melitus tipe 2 . Portal Garuda Dikti.

Raman, R., Kumari, P.R., Reddi, S.R., Gnanamoorthy, P., Uthra, S., Kumaramanickavel, G., Sharma, T. (2009). Prevalence Of Diabetic Retinopathy In India. Elsevier. American Academy of Ophtalmology

Shah, C. A .(2008). Diabetic Retinophaty : $A$ Comprehensive Review.http://www.indianjmed 
sci.org/ di unggah pada tanggal 25Agustus 2018.

Wong Jencia, Molyneaux L.(2008).

Timing is Everthing: Age of Onset Influence Long Term Retinopathy Risk in Type 2 Diabetes, Independent of Tradisional Risk Faktors. Diabetes Care. Volume 31:1985-1990.

Liu S, Tinker L, Song Y, Rifai N, Bonds DE, Cook NR, et al. (2007). A prospective study of inflammatory cytokines and diabetes mellitus in multiethnic cohort of postmenopausal women. Arch Intern Med. 2007;167(15):1676.

Boelter MC, Canani LH, Lisboa HR, Lavinzky J, Azevedo MJ. (2006). Proliferative diabetic retinopathy is associated with microalbuminuria in patient with type 2 diabetes. Braz $\mathrm{J}$ Med Biol Res. 39:1035.

Williams R, Airey M, Baxter H, Forrester J, Kennedy-Martin T, Girach A. (2004). Epidemiology of diabetic retinopathy and macular oedema: a systematic review. Eye :18:963-83.

Eid, M., Mafauzy, M. and Faridah, A.R. (2003). Glycaemic Control of Type 2 Diabetic Patients on Follow Up at Hospital Universiti Sains Malaysia. Malaysian Journal of Medical Science. 10(2): 40-49..

PERKENI. Konsensus dan Pencegahan Diabetes Melitus
Tipe 2 di Indonesia. Jakarta.2006

Pandelaki, K. (2006). Buku Ajar Ilmu Penyakit Dalam. Jakarta : Pusat Penerbitan Ilmu Penyakit Dalam Fakultas Kedokteran Universitas Indonesia. pp : 1911-1915.

Suyono,dkk. Diabetes Melitus di Indonesia, dalam: Buku Ajar Ilmu Penyakit Dalam.(2006). Edisi keempat jilid III. Balai Penerbit FK UI,Jakarta.

Massimo, P., Curletto, G., Cipullo, D., Rigault, R.L., Trento, M., Passera, P., Viola, A.T., Miceli, S., Cenci, A., Dalmasso, P., Cavallo, F.( 2014). Estimating the Delay Between Onset and Diagnosis of Type 2 Diabetes From the Time Course of Retinopathy Prevalence. Diabetes Care. 37:1668-1674.

Ilyas Sidarta. (2008). Mata Tenang Penglihatan Menurun, dalam Penuntun Ilmu Penyakit Mata. Edisi ke tiga. Fakultas Kedokteran Universitas Indonesia, Jakarta. 2008; h. 142-143.

Grady D. (2006) Management of menopausal symptoms. N Engl J Med. 2006:355:2338.

Mulyati, Ramzi, Santoso. (2015). Kemajuan Visus Penderita Retinopati Diabetik yang Diterapi dengan Laser Fotokoagulasi dan atau Injeksi Intravitreal di Rumah Sakit Mohammad Hoesin Palembang. Majalah 
Kedokteran Sriwijaya. volume 47, No. 2.

Votey Scott, Peters Anne. (2010). Diabetes Mellitus Type 2. Emedicine Specialties.

Boelter MC, Canani LH, Lisboa HR, Lavinzky J, Azevedo MJ. (2006). Proliferative diabetic retinopathy is associated with microalbuminuria in patient with type 2 diabetes. Braz $\mathrm{J}$ Med Biol Res. 39:1035.

Wild Sarah, Roglic Gojka. (2004). Global Prevalence of Diabetes.
Diabetes Care.(2004); volume 27: 1047-1053.

Hoogwerf B.J. (2005). Complication of Diab etes Mellitus. http://www.ijddc. com/text.asp?2005/25/3/63/227 74 (2 September 2018)

Reaven G. (2003) Age and glucose tolerance. 2003;26:1-2 